\title{
Stem Cells: Background, Prospects and Potential Applications in Tanzania: A review
}

\author{
Afadhali Denis Russa \\ Department of Anatomy, School of Medicine, Muhimbili University of Health and Allied Sciences (MUHAS), Dar es \\ Salaam, Tanzania.
}

\begin{abstract}
Stem cell technology and its application in regenerative medicine is the future gateway for the treatment of most non-communicable diseases (NCDs). As the burden of NCDs continues to rises globally, regenerating the cells, tissues and organs will be the mainstream treatment option. The world is prepared for this intriguing but promising avenue of biomedical technology and medicine but Africa is grossly lagging far behind. African governments, universities, research and health institutions need to take a leading role in empowering and mainstreaming stem cell research. Moreover, for Africa there is a huge potential for translating stem cell technology into clinical treatments due to the fact that there are limited treatment options for life threatening forms of NCDs. Some African countries have well developed stem cell facilities and large-scale stem cell therapy centers. The use of adult stem cells in liver failure, diabetes and cardiac infarcts has shown success in some African countries. The present work reviews the status, potential and future prospects of stem cell technology and regenerative medicine in Tanzania with particular emphasis on the adult stem cells applicability into the immediate use in patient care. The paper also reviews the available cell identification systems and markers and moral and ethical aspects of stem cell science necessary in the translational treatment regimens.
\end{abstract}

Keywords: Stem cells, Application, NCDs, Tanzania

\section{Background}

Stem cell technology and its regenerative or reparative benefits is the future gateway for medical treatment. Stem cells have shown an immense potential in the treatment of diseases which have traditionally been considered degenerative, incurable and irreversible such as diabetes, heart diseases, spinal cord injuries, Parkinson's, Alzheimer's disease which has attracted global interest and curiosity (Mittal, 2013). Currently crude data show that the non-communicable diseases are the leading cause of mortalities globally but the trend is currently vice versa for Africa (Fig. 1). The World Health Organization (WHO) Global burden of Disease reports have shown that by 2030 the noncommunicable diseases such as cancers, cardiovascular and degenerative diseases will surpass the infectious diseases even in the low- and middle-income countries including Tanzania (Fig. 2). Overall, non-communicable conditions (NCDs) are projected to account for over three quarters of all deaths in 2030 (WHO, 2008). As the burden of the non-communicable diseases continues to rises globally, regenerating the cells, tissues and organs is focused to be the mainstream treatment option. While the world is prepared for this intriguing but promising avenue of biomedical technology and medicine, Africa is grossly lagging far behind the other continents. African governments especially and development stake holders in general need to take a leading role in empowering and mainstreaming stem cell research and cell-based therapies in African research facilities, universities and hospitals. The present work reviews the status, potential and future prospects of stem cell technology and regenerative medicine in Tanzania with particular emphasis on the adult stem cells applicability into the immediate use in patient care. Very specially the paper also calls for the scientists, clinicians, policy makers, government agencies and regulatory bodies to vehemently team up to gear forwards the stem cell and regenerative medicine agenda in Tanzania in the light of the developments occurring in the field regionally and globally. 
Table 1: Leading causes of death by income group 2004 (WHO 2008 update)

\begin{tabular}{|c|c|c|c|c|c|c|c|}
\hline & Disease or injury & $\begin{array}{r}\text { Deaths } \\
\text { (millions) }\end{array}$ & $\begin{array}{r}\text { Per cent } \\
\text { of } \\
\text { total } \\
\text { deaths }\end{array}$ & & Disease or injury & $\begin{array}{r}\text { Deaths } \\
\text { (millions) }\end{array}$ & $\begin{array}{r}\text { Per cent } \\
\text { of } \\
\text { total } \\
\text { deaths }\end{array}$ \\
\hline & World & & & & Low-income countries & & \\
\hline 1 & Ischaemic heart disease & 7.2 & 12.2 & 1 & Lower respiratory infections & 2.9 & 11.2 \\
\hline 2 & Cerebrovascular disease & 5.7 & 9.7 & 2 & Ischaemic heart disease & 2.5 & 9.4 \\
\hline 3 & Lower respiratory infections & 4.2 & 7.1 & 3 & Diarrhoeal diseases & 1.8 & 6.9 \\
\hline 4 & COPD & 3.0 & 5.1 & 4 & HIV/AIDS & 1.5 & 5.7 \\
\hline 5 & Diarrhoeal diseases & 2.2 & 3.7 & 5 & Cerebrovascular disease & 1.5 & 5.6 \\
\hline 6 & HIV/AIDS & 2.0 & 3.5 & 6 & COPD & 0.9 & 3.6 \\
\hline 7 & Tuberculosis & 1.5 & 2.5 & 7 & Tuberculosis & 0.9 & 3.5 \\
\hline 8 & Trachea, bronchus, lung cancers & 1.3 & 2.3 & 8 & Neonatal infections ${ }^{b}$ & 0.9 & 3.4 \\
\hline 9 & Road traffic accidents & 1.3 & 2.2 & 9 & Malaria & 0.9 & 3.3 \\
\hline 10 & Prematurity and low birth weight & 1.2 & 2.0 & 10 & Prematurity and low birth weight & 0.8 & 3.2 \\
\hline
\end{tabular}

Table 2: Projected global deaths for selected causes 2004-2030 (WHO 2008 update)

Figure 16: Projected global deaths for selected causes, 2004-2030

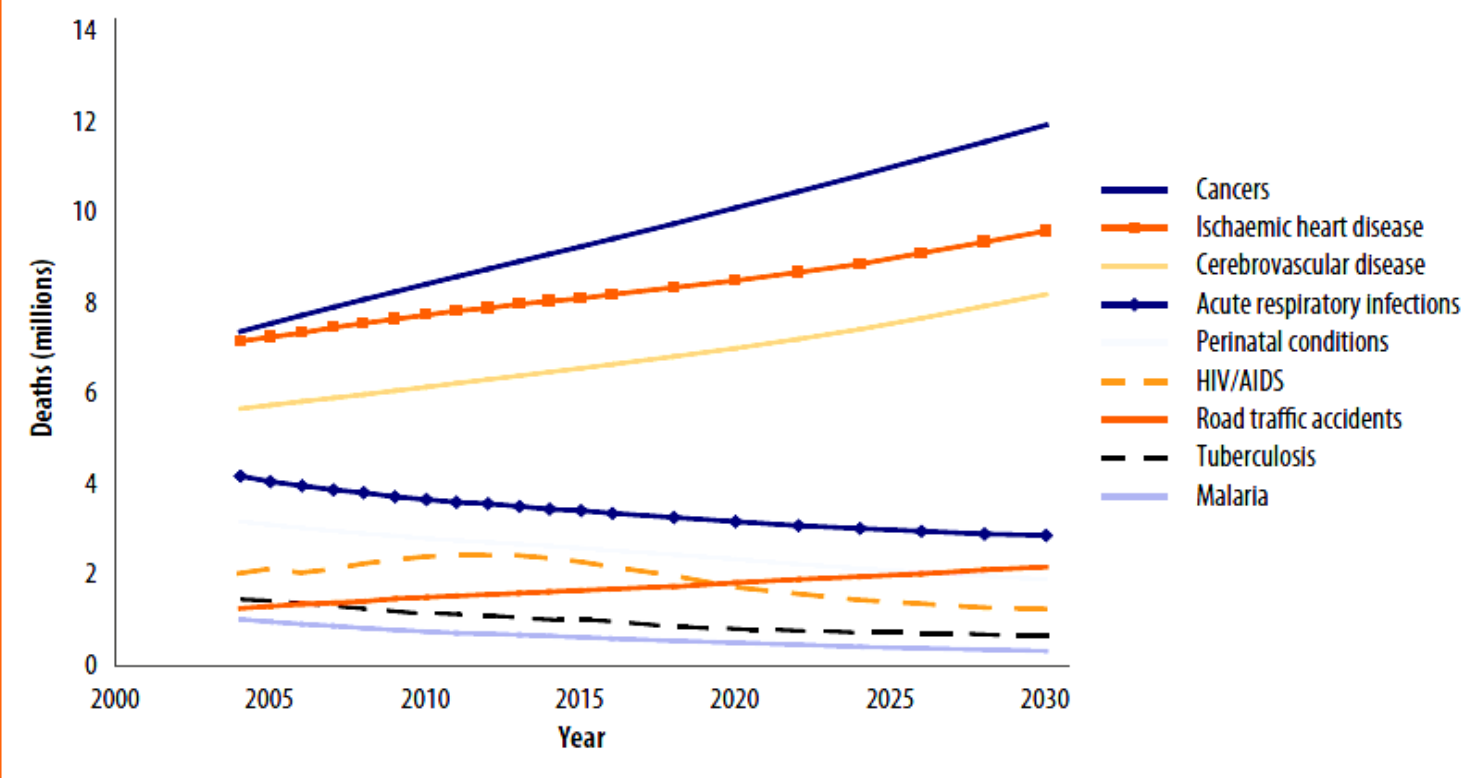

African perspective and status of the stem cell research 
Africa lags behind other continents in stem cell technology. The reasons for this slow pace being poor expertise and physical infrastructure, low funding, lack of regulation and the high burden of communicable diseases among other factors. Despite all these continental hitches some African countries have well developed stem cell facilities including large scale clinical level stem cell therapies. Definitive methods of treatments of autologous cell therapies are now being carried out extensively in some African countries such as Tunisia and Egypt. While most other African countries largely still struggle with the quest of how to harness the huge potential of stem cell therapy against the odds of ethical, moral, regulatory and technical capacity dilemma (Agbedia \& Oshegbo, 2013), concerted national efforts are needed to set up an initial research centre and clinical facilities in Tanzania. Small scale use of imported adult type stem cells such umbilical cord or bone marrow hematopoietic stem cells has been tried for the management of sickle cell anemia among children in Tanzania and sustainability of these initial endeavors remains a major challenge. These efforts therefore need to be supported by research infrastructure and capacity building of the local workforce both at preclinical and clinical levels. In the neighboring Kenya, the KAVI Institute of Clinical Research (KAVI-ICR) in Nairobi is forging ahead into the field with the establishment of a stem cell bio-bank. Preliminary data on cultured cord blood mesenchymal stem cells are being generated and mini-clinical trials using adult stem cells in managing burns and chronic wounds are underway. Team work between basic and clinical departments of the College of Health Sciences of the University of Nairobi (UNO) have been established which is a major prerequisite in the translation of stem cell technology from bench to bed side. More importantly national regulatory standards, policies and advocacy have been established and being expanded (Utafiti News, 2016). Pertinent to its great and promising potential, the field of regenerative medicine needs to be dealt with care and strict regulations. Reports of fake stem cell based therapies are rampant in Africa especially and elsewhere (Pepper, 2010; Tawari \& Raman, 2014). These threats therefore may hamper the use and acceptability of stem cell therapy right from the beginning.

\section{Stem cell markers in basic and clinical settings}

For many years stems cells have traditionally been classified into embryonic stem cells (ES) and adult (Mafi et al., 2011) or mesechymal stem cells (MSCs). A third category-the induced pluripotent stem cells (IPSC) - is a relatively recent discovery by Yamanaka and co-workers in a ground-breaking work that eventually won a Nobel Prize in 2012. The major challenge with stem cells in general is their identity. Universally acceptable identification system and markers are absent (Mafi et al., 2011) and definitive markers that have been identified tend also to mark some tumor and other defective cells (Knoepfler, 2009). And for embryonic stem cells, in addition to their strict ethical and moral regulations they have rigorous culture and maintenance protocols. Moreover, embryonic stem cells have the potential of being able to clone a human-an aspect that may open the door of moral and ethical controversies. Due to these moral and ethical dangers, research has recently focused towards the adult stem cells generally referred to as mesenchymal stem cells (MSCs). Identification of MSCs is fairly well documented and their definitive markers are well understood, easy to handle and maintain under in vitro conditions. Additionally, MSCs are readily available in almost all body tissues (da Silva et al., 2006).

Based on the stem cell differentiation potential, however, a more elaborate classification system defines stemness levels into five categories namely: totipoteny, pluripotency, multipotency, oligopotency and unipotency. Totipotency is generally defined as the ability of a single cell to divide and produce all the definitive cells in an organism including the extraembryonic tissues such as the placenta and the amnion - a trait only exhibited by the zygote to the level of the morula (Seydoux \& Braun, 2006). Other researchers have defined totipotency as not to necessarily possess the capacity to differentiate into the extra-embryonic tissues. In general the earliest stages of development from 
the zygote to the morula embryonic stages constitute the totipotency whereas the stages that follow-formation of the inner cell mass and the epiblast cells-mark the beginning of pluripotency (Mitalipov \& Wolf, 2009). Pluripotent stem cells which result from gastrulation process have the ability to differentiate into all of the cell types from the three germ layers-ectoderm, mesoderm and endoderm. Further products of differentiation pathways that follow gastrulation into the three germ layers can form several tissues and hence constitute the multipotent stem cells. Uses of stem cells from tortipotency to multipotency normally require the sacrifice of the entire embryo and are always classified as the emberyonic stem cells (ESCs) —an aspect that has faced intense ethical and moral challenges leading to limited potentials in their applicability in regenerative medicine. Several adult cellular and tissue models have been developed including cardiomyocytes envisaged to regenerate myocardial cells in cardiac infarcts (Kehat et al., 2001). However, so far there is no clinically proven use of the embryonic stem cells anywhere in Africa and in the world. Reprogramming of adult cells into the induced pluripotential stem cells (IPSCs) also give rise to cells with a differentiation potential similar to the cells of the inner cell mass or epiplast as described by the infamous Takahashi and Yamanaka pioneering work that won a Nobel Prize in 2012 (Takahashi \& Yamanaka, 2006).

As previously noted, the field of stem cell and regenerative medicine has recently focused on the use of adult stem cell which are either multipotent, oligopotent or unipotent. These are progenitor cells with variable potential to differentiate into definitive cells of the body. Multipotent cells can form several related mature cells of one or two related body systems and these form the major target of the adult stem cells deemed as a crucial target in regenerative medicine. While there are variability in the identity and markers, adult stem cells must meet the minimal criteria which include plasticadherence when maintained in standard culture media and the ability to express CD105, CD73 and CD90. The positive markers - the CD105 also called endogolin, CD73 (NT54 gene encoded) and CD90are cluster differentiation (CD) cell surface receptors consistently expressed by MSCs cells although they can be expressed by some cancer cells also. The MSCs minimal criteria also identify the negative markers of CD45, CD34, CD14 or CD11b, CD79alpha or CD19 and HLA-DR surface molecules. As part of the minimal criteria the MSCs must have the ability to differentiate into osteoblasts, adipocytes and chondroblasts in in vitro culture (Dominici et al., 2006; Wang et al., 2016). A subset of adult stem cells constitutes cancer stem cells which are rare but may be fatal if not well identified. Therefore, cancer stem cells identification is important in order to monitor any abnormalities of cells turning into tumor types. Cancer stem cells of different tissue origin express certain CD44, CD133, CD24, CD90, CD271, CD49f and CD13. CD44 is a prominent trans-membrane glycoprotein marker of cancer stem cells of various tumors. For instance, the basal cells of normal bladder urothelium express CD44, which is being used as a marker for bladder, breast, pancreas, gastric, prostate and colon cancer. A much unique subset of the adult stem cells is the hematopoietic stem cells (HSCs) which have the gene activation potential to differentiate in all white blood cell types. HSCs have been extensively studied and the transplantation of these tissue-specific stem cells has now become a standard-of-care for numerous hematological indications such as bone marrow transplant (BT) and will not be further dealt with in the current review.

\section{Potential use of adult stem cell therapy in Tanzania}

In the increasing era of non-communicable diseases such as cancer and diabetes mellitus stem cell therapy is expected to play a major role in managing the burden of diseases. Use of stem cell infusion for patients on chemotherapy and radiotherapy to restore tissue regeneration due to side effects of chemotherapy and radiotherapy is currently at a clinical stage in some African countries and elsewhere in the world. Several treatments with stem cell therapy have been possible due to the fact that patients who benefit from stem cell therapy have very limited treatment options such as end-stage liver cirrhosis and heart failure - a situation where the benefit outweigh the adverse outcomes of trial 
treatments. And in Tanzania where advanced treatment such as liver transplant is inexistent the use of stem cells can substantially benefit these desperate patients. Use of stem cells in the treatment of chronic non-communicable diseases is underway in some African health institutions. Easy and freely accessible methods for isolation and characterization have been proposed. Protocols for isolation of adult stem cells from various tissues/ organs have been tried and proven including the umbilical cord and Wharton jelly ( Maleki et al., 2014; Beeravolu et al., 2017), spermatogonia and oogonia (Maleki et al., 2014) and bone marrow (Salama et al., 2014). Handy and practical methods and routes of administration of the cells into patients of liver cirrhosis have been previously reviewed (Jameson, 2008). Commonly used markers are of the CD family plasma membrane receptors which can be characterized using commercially available monoclonal antibody kits coupled with con-focal live microscopic imaging, fluorescent in situ hybridization (FISH) or western blotting. We have previously shown the regenerative potential of the fibroblast-like cells isolated from the subcutaneous tissue (Russa, 2014). In fact, these cells showed signaling prowess indicating their vitality in regeneration and growth. In one study strong signaling via a capacitative calcium entry (CCE) supported the possibility of the cellular regenerative potential (Russa et al., 2009).

At the bedside use of stem cells therapy is gaining momentum even on the African continent. In the realms of regenerative medicine, the treatment of chronic non-communicable diseases such as cirrhosis, diabetes and cardiac infarction has always relied heavily on adult stem cells with multipotential, oligopotential or unipotential capabilities. Chemical treatments are used to induce differentiation into a specific cell type using special media. In a series of studies at the Hepatology and Tropical Medicine Institute in Cairo, over 150 post-hepatitis C end-stage liver disease patients treated with ex-vivo culture-amplified autologous mesenchymal stem cells showed reversal of a wide range of grave indicators of disease including albumin, bilrubin, increased international normalized ratio (INR), prothrombin concentration and alanine transaminase (ALT) levels and the stabilization of clinical and biochemical variables. These improvements were not reproduced in control patients who were being managed under conventional end-stage liver cirrhosis palliative treatment (Salama et al., 2010; Salama et al., 2014). In Egypt alone there were about eight stem cell research and therapy centres in 2008 serving over 75 million populations and more than 1300 cell therapy transplants among patients had been treated with various levels of success (Mahmoud et al., 2008). Therefore, the concept of regenerative medicine is becoming a common practice among the African countries. In a phase 2 clinical trial by Tunisian health researchers among eight patients with end-stage liver cirrhosis due to Hepatitis B and C, alcoholism and of cryptogenic causes, liver function was significantly restored and the treatment well tolerated by the patient (Kharaziha et al., 2009). In a similar study by Egyptian researchers, reported improved in ascites and prothrombin time after a 3-month treatment of 20 cirrhotic patients using autologous bone marrow-derived MSCs ( Salama et al., 2014).

While most of the novel treatments have involved liver diseases, several successful treatments of the heart failure and other types of NCDs particularly of autoimmune nature are making promising clinical application even on the African continent. Tanzania has a huge number of heart failure cases which when stem cell treatment becomes available many will benefit. Possible treatment of type 1 Diabetes mellitus using various sources of mesenchymal stem cells including bone marrow, adipose tissue, placenta cord blood and Wharton's jelly is extensively reviewed by clinical researchers at the University of Khartoum in Sudan (Babiker et al., 2017). Further, a relatively easy IV infusion of allogeneic umbilical cord messechymal stem cells (UC-MSCs) to patients with heart failure and reduced ejection fraction recently reported by Bartolucci and co-coworkers has shown clinically promising outcomes. UC-MSCs in vitro compared with bone marrow-derived mesenchymal stem cells displayed a 55-fold increase in the expression of hepatocyte growth factor, known to be involved in cardiomyocyte proliferation, cell migration, and immunoregulation. UC-MSC-treated patients presented no adverse events related to the cell infusion and none of the patients tested during the 
follow ups did present alloantibodies to the UC-MSCs among all seven patients enrolled. The treatment group exhibited significant improvements in left ventricular ejection fraction at 3, 6, and 12 months of follow-up as assessed both through transthoracic echocardiography (Bartolucci et al., 2017).

\section{Law, Policy, Regulation and Advocacy}

While there are some preliminary efforts that are underway including the creation of a national task force for Organ Transplantation in Tanzania, the country needs to have solid tissue and stem cell laws and policies to regulate, advocate and mainstream this important and novel field which is soon envisioned to be the mainstay of treatment of non-communicable diseases. Legal documents in form of laws and policies are needed in order to balance the scientific freedom with public health protection especially in the era where global reports of fake therapies and radical scientific endeavors are reported globally and are widespread. In the neighboring Kenya, the new Health Bill (Kenya Laws, 2015) has provided for the use of stem cells in medical practice and health research. Coupled with the establishment of the guiding laws and regulations a national research and translational centre of excellence is hastily needed to gear forward the field of regenerative medicine in Tanzania.

Medical schools and healthcare institutions need to establish locally collaborating centers of excellence and design curricula in basic, applied and clinical academic programs to streamline regenerative medicine in to embrace the upcoming novel medical technologies and therapies in this field. Due to the complexity of stem cell technology and its translation in clinically useful disease treatments, a national forum which involves together the academia, industry, government, patient/provider organizations, regulators, and foundations is needed to bring difficult issues to common solutions. On the African continent there have been efforts spearheaded by the African Academy of Sciences (AAS) based in Nairobi, Kenya to promote and build capacity in Stem Cell and Regenerative Medicine in Africa. However due to the fact that these efforts were not supported by individual national budgets, plans and policies, the efforts seem to have stagnated recently. These forums should be able to address challenges facing the field of regenerative medicine, including the potential barriers to scientific and therapeutic advances, the discovery, development, and translation of regenerative medicine therapies. More challenges also involve identifying, validating and bringing regenerative medicine applications into the market and the ethical, legal, and social issues posed by regenerative medicine advances.

\section{Ethics, Safety and Misuse}

Stem cell ethical and moral dilemma and skepticism has been around since the idea of stem cells first came into existence more than a century ago ( Bianco et al., 2008; Afanasyev et al., 2009). The regulation of stem cell use has probably been a major setback than the availability of the expertise itself. The question as to when life begins has always eluded a common ground of agreement from the spiritual, scientific, political and legal perspectives (Agbedia \& Oshegbo, 2013). Even in those countries with loose ethical and legal regulation the moral and spiritual sentiments remain high hampering the growth of the field. In the rush for profits private companies and agencies tend to market their cellbased therapies without going through safety and quality checks (Cyranoski, 2012; Pepper, 2010). The marketing of unproven treatments raises major ethical and integrity issues and can easily put the safety of patients in jeopardy. One of the most famous fraudulent therapies is of a 13-year old Israeli boy who was treated in Russia with intracerebellar and intrathecal injection of human fetal neural stem cells in Russia and four years later developed a multifocal brain tumor that needed a neurosurgical intervention (Amariglio et al., 2009). While the use of embryonic stem cell therapies is still a challenge globally some companies such as Nutech Mediworld in New Delhi, India, claims successful clinically proven treatments which are aggressively y advertized on the Internet. Lessons should be learnt from 
countries such as India where stem cell therapies are generally at advanced levels but loosely regulated giving occasion for some private health facilities to advertise fraudulent treatment outcome and efficacy of stem cell therapies under faked approval certifications from regulatory bodies (Pandya, 2008; Sipp, 2009; Tawari \& Raman, 2014).

Due to the uniqueness of stem cell-based therapies new treatment regimens need thorough and rigorous testing before they are approved for universal adoptions as standard methods of disease monument. The International Society for Cell and Gene Therapy (ISCT) based in Vancouver, Canada, has scaled up a global surveillance and advice against the use of unproven stem cell therapies. In the quest to standardize the clinical use of the stem cell and regenerative medical procedures, ISCT stipulates the procedures, facilities, expertise, outcome and the regulations needed for genuine therapies. These standards aren't frequently honored in some countries though and least do they trickle down to developing countries in Africa to influence and promote growth in the field of stem cell and regenerative medicine.

\section{Conclusions and recommendation}

Stem cell technology and therapy is the future mainstay for managing non-communicable diseases. As it is now, Tanzania and indeed the majority of African countries, is not yet prepared. Deliberate and multifaceted efforts from scientists, clinicians, policy makers and politicians are needed to work together in order to gear forward the agenda. Medical schools, research centers government agencies and relevant ministries need to be at the forefront in initiating and lying up necessary infrastructure and environments for this new era of science and medicine.

\section{References:}

Afanasyev, A. J., Elstner, E., \& Zander, A. R. (2009). A.J.Friedenstein, founder of the mesenchymal stem cell concept. Cellular Therapy and Transplantation 1(3), e.000029.000001.

Agbedia, C. O., \& Oshegbo, G. I. (2013). The challenges of stem cell research in Nigeria International Journal of Advanced Nursing Studies, 2(2), 52-57.

Amariglio, N., Hirshberg, A., Scheithauer, B. W., Cohen, Y., LoeweNthal, R., Trakhtenbrot, L., et al. (2009). Donorderived brain tumor following neural stem cell transplantation in an ataxia telangiectasia patient. PloS Med, 6(2), e1000029.

Babiker, N. E., Gassoum, A., Abdelraheem, N. E., Arbab, M. A., Al Deaf, S. A. H., El-Sheikh, M. A. A., et al. (2017). The progress of Stem cells in the treatment of diabetes mellitus type 1. Progress in Stem Cell 4(1), 175188.

Bartolucci, J. G., Verdugo, F. J., González, P. L., Larrea, R. E., Abarzua, E., Goset, C., et al. (2017). Safety and Efficacy of the Intravenous Infusion of Umbilical Cord Mesenchymal Stem Cells in Patients With Heart Failure: A Phase 1/2 Randomized Controlled Trial Circulation Research 117, 310712.

Beeravolu, N., McKee, C., Alamri, A., Mikhael, S., Brown, C., Perez-Cruet, M., et al. (2017). Isolation and Characterization of Mesenchymal Stromal Cells from Human Umbilical Cord and Fetal Placenta. Journal of Visualized Experiments, 122.

Bianco, P., Robey, P. G., \& Simmons, P. J. (2008). Mesenchymal stem cells: revisiting, history and assays. Stem Cell, 2(4), 313-319.

Cyranoski, D. (2012). China's stem cell rules go unheeded. Nature, 484, 149-150. da Silva Meirelles, L., Chagastelles, P. C., \& Nardi, N. B. (2006). Mesenchymal stem cells reside in virtually all post-natal organs and tissues. J Cell Sci., 119(11), 2204-2213.

Dominici, M., Le Blanc, K., Mueller, I., Slaper-Cortenbach, I., Marini, F., Krause, D., et al. (2006). Minimal criteria for defining multipotent mesenchymal stromal cells. The International Society for Cellular Therapy position statement. Cytotherapy, 8(4), 315-317.

Jameson, E. ( 2008). Cellular Transplantation for Liver Diseases. Gastroenterology Res., 1(1), 8-13. 
Kehat, I., Kenyagin-Karsenti, D., Snir, M., Segev, H., Amit, M., Gepstein, A., et al. (2001). Human embryonic stem cells can differentiate into myocytes with structural and functional properties of cardiomyocytes. $J$ Clin Invest, 108(3), 407-414.

Kharaziha, P., Hellström, P. M., Noorinayer, B., Farzaneh, F., Aghajani, K., Jafari, F., et al. (2009). Improvement of liver function in liver cirrhosis patients after autologous mesenchymal stem cell injection: a phase I-II clinical trial. Eur J Gastroenterol Hepatol. 2009 Oct;21(10):1199-205. doi: . Eur J Gastroenterol Hepatol, 21(10), 1199-1205.

Knoepfler, P. S. (2009). Deconstructing Stem Cell Tumorigenicity: A Roadmap to Safe Regenerative Medicine. Stem Cells, 27(5), 1050-1056.

Laws, K. (2015). National Assembly Bills: The Health Bill. Kenya Gazette Supplement 44(Assembly 14), Articles 2, 48.

Mafi, P., Hindocha, S., Mafi, R., Griffin, M., \& Khan, W. S. (2011). Adult Mesenchymal Stem Cells and Cell Surface Characterization - A Systematic Review of the Literature. Open Orthop J., 5, 253-260

Mahmoud, H., El-Haddad A, Fahmy O, El-Emary M, Nassar A, Abdel-Mooti M, et al. (2008). Hematopoietic stem cell transplantation in Egypt. Bone Marrow Transplant. 2008 Aug;42 Suppl 1:S76-S80. doi: 10.1038/bmt.2008.136., 42 Suppl 1(76-80).

Maleki, M., Ghanbarvand, F., Reza Behvarz, M., Ejtemaei, M., \& Ghadirkhomi, E. (2014). Comparison of Mesenchymal Stem Cell Markers in Multiple Human Adult Stem Cells. International Journal of Stem Cells, $7(2), 118-126$.

Mitalipov, S., \& Wolf, D. (2009). otipotency, pluripotency and nuclear reprogramming. Adv Biochem Eng Biotechnol., 114, 185-199.

Mittal, S. (2013). Stem cell research: The India perspective. Perspect Clin Res. , 4(1), 105-107

Pandya, S. K. (2008). Stem cell transplantation in India: Tall claims, questionable Ethics. Indian Journal of Medical Ethics 5, 16-18.

Pepper, M. S. (2010). Cell-based therapy - navigating troubled waters. South African Medical Journal, 100(5), 286288.

Russa, A. D. (2014). Bromodeoxyuridine immunofluoresence and differential interference contrast imaging combination can precisely segregate adherent monolayer cells into specific cell-cycle phases. Tanzania Journal of Health Research, 16(2), 131-135.

Russa, A. D., Maesawa, C., \& Satoh, Y. (2009). Spontaneous [Ca2+] i oscillations in G1/S phase-synchronized cells. Journal of Electron Microscopy, 58(5), 321-329.

Salama, H., Zekri, A. R., Zern, M., Bahnassy, A., Loutfy, S., Shalaby, S., et al. (2010). Autologous hematopoietic stem cell transplantation in 48 patients with end-stage chronic liver diseases. Cell Transplant. 19(11):147586., 19(11), 1475-1486.

Salama, H., Zekri, A. R. N., Medhat, E., Al Alim, S. A., Ahmed, O. S., Bahnassy, A. A., et al. (2014). Peripheral vein infusion of autologous mesenchymal stem cells in Egyptian HCV-positive patients with end-stage liver disease. Stem Cell Research \& Therapy, 5(3), 70.

Seydoux, G., \& Braun, R. E. (2006). Pathway to totipotency: lessons from germ. Cell, 127(5), 891-904.

Sipp, D. (2009). Stem cell research in Asia: A critical review. Journal of Cellular Biochemistry 107, 853-856.

Takahashi, K., \& Yamanaka, S. (2006). Induction of pluripotent stem cells from mouse embryonic and adult fibroblast cultures by defined factors. Cell 126(4), 663-676.

Tawari, S. S., \& Raman, S. (2014). Governing stem cell therapy in India: regulatory vacuum or jurisdictional ambiguity? New Genetics and Society 33(4), 413-433.

Wang, L. T., Ting, C. H., Yen, M. N., Liu, K. J., Sytwu, H. K., Wu, K. K., et al. (2016). Human mesenchymal stem cells (MSCs) for treatment towards immune- and inflammation-mediated diseases: review of current clinical trials. Journal of Biomedical Science 23:76

WHO. (2008). The global burden of disease: 2004 update. 